\title{
Gemcitabine-vinorelbine-prednisolone combination in cases with lymphoma: retrospective analysis
}

\author{
Semra Paydas ${ }^{*}$, Emine Kilic Bagir ${ }^{2}$ and Melek Ergin ${ }^{2}$ \\ ${ }^{1}$ Faculty of Medicine, Departments of Medical Oncology, Cukurova University, Adana, Turkey \\ ${ }^{2}$ Faculty of Medicine, Departments of Pathology, Cukurova University, Adana, Turkey
}

\begin{abstract}
Objective: The aim of this study is to evaluate the response rate with gemcitabine-vinorelbine-prednisoloe (GVP) combination in cases with relapsed/refractory lymphoma.

Method: Forty-four patients with lymphoma, 22 with Hodgkin lymphoma (HL) and 22 with non-Hodgkin lymphoma (NHL), treated by GVP combination regimen were evaluated retrospectively.

Results: Complete response (CR) and partial responses (PR) were detected in 6 and 8 cases, respectively and overall response rate was 63.63\% in cases with HL. Although autologous stem cell transplantation could be done in only 2 cases, long term survival was achieved in cases responsive to GVP regimen. Among NHL cases only $1 \mathrm{CR}$ and $3 \mathrm{PRs}$ were detected in cases with diffuse large B cell lymphoma with 5-7 months response duration. One minimal response and 1 PR were detected in 2 cases with peripheral $\mathrm{T}$ cell lymphoma with 2-4 months of response duration. There was no response in grey zone lymphomas.
\end{abstract}

Conclusion: GVP regimen is highly active in cases with HL both in primary refractory and also relapsed/refractory (R/R) HL cases and may be performed in outpatient clinic.

\section{Introduction}

High dose chemotherapy (HDCT) and autologous stem cell transplantation (ASCT) is standard of care in relapsed and/or refractory cases with HL and NHL. However, there is no optimal salvage regimen in these cases. Both HL and NHL are curable disease among malignant diseases, but $20-40 \%$ of the cases relapse. Salvage treatment with noncross resistant drugs is standard approach in fit patients. Response to salvage regimen is very important for ASCT and long-term survival. However, there is no ideal salvage regimen and it is critical to obtain maximum response [1-3]. Of course, all patients are not fit enough for ASCT due to co-morbidities and/or patients' preferences. For this reason, ideal regimen must have a potential for higher response rate with long remission duration and acceptable toxicity profile. There are many combination treatments for this aim [4-6]. DHAP and ICE are the most commonly used salvage regimens and CORAL study is the only Phase III randomized study at this field [8]. The two important points are the heterogeneity of lymphomas and also doctors treating these patients.

Gemcitabine containing regimens are important choices in daily practice and response rates with these combinations may be as high as 70-85\% [9]. These are effective regimens with acceptable toxicity profile allowing stem cell collection and also to use in outpatient clinics.

Here we presented 44 cases with lymphoma treated by GVP regimen and discussed available literature.

\section{Patients and methods}

Forty-four cases with lymphoma treated by GVP regimen were evaluated retrospectively. Twenty-two of the cases had HL and 22 had NHL. GVP regimen was performed in every 3 weeks with G-CSF support. Gemcitabine was given $800 \mathrm{mg} / \mathrm{m} 2$ in days 1 and 8 , vinorelbine was given $25 \mathrm{mg} / \mathrm{m}^{2}$ in days 1 and 8 and prednisiolone was given 100 mg per day between 1 and 8th days. Rituximab was added in cases with CD20 expression.

Patients were treated in outpatient clinic. Response was assessed with standard criteria after 3 cycles of treatment by using PET/CT and /or CT scanning's. ASCT was performed in cases with at least PR after 3 cycles. GVP regimen was given for six cycles in patients rejecting ASCT and showing at least PR.

\section{Findings}

Forty-four patients with lymphoma were included in this retrospective analysis. Age range was between 18 and 77; 19 of them were female and 25 were male. Twenty-two of the cases had HL and 22 had NHL.

\section{HL cases}

Age range was between 21-59; mean age was $40.4 \pm 14.3$, female/ male ratio was 10/12. All the patients had been treated by ABVD regimen as first line therapy. Three of the cases had primary refractory

Correspondence to: Semra Paydas, Faculty of Medicine, Department of Medical Oncology, Cukurova University 01330 Balcali Adana/Turkey, Tel: +90 322 3386060; E mail: sepay@cu.edu.tr

Key words: lymphoma, relapse, refractory, salvage regimen, gemcitabine containing regimen

Received: November 20, 2017; Accepted: December 15, 2017; Published: December 18, 2017 
disease, 5 cases had relapse disease before 12 months and 14 cases had relapse after 12 months from the end of first line treatment.

GVP regimen was given as first line salvage therapy in 3 cases. CR was detected in 2 of these 3 cases: one did not accept ASCT, and is in CR more than 25 months after GVP. Nivolumab was given to the second patient after progression of the disease and she is still receiving immunotherapy, response duration to GVP was 4 months in this case. Progressive disease (PD) developed in third case, and he died in spite of bendamustine and brentuximab vedotin (BV) treatments.

GVP regimen was given as second line salvage treatment to 19 cases; 3 of them had primary refractory disease, PD was detected in 2 cases and they died with disease progression. One of these 3 cases achieved CR and ASCT was performed and she is alive (118+ months). Sixteen patients had relapse disease after than 12 months; DHAP, ICE and local radiation had been given to 13,2 and 1 cases, respectively. Among these cases CR was detected in 3 cases; ASCT was rejected by the patients and they are alive (6-90+ months). PR was detected in 6 cases; ASCT was performed in one case and she is alive, five cases rejected ASCT; PD occurred in 4 cases: 3 died one lost to follow up. Five cases relapsing less than 12 months and receiving GVP as second line salvage, PR was detected in 2 cases and remission duration was 6 months in one. Other case was in remission for 25 months with GVP regimen. BV and bendamustine were given after progression and lastly, she is receiving nivolumab. CR was achieved in one case, remission duration was 35 months, IGEV and then BV were given for relapses, but she died with progression. PD developed in 2 cases; one lost to follow up and second died in spite of bendamustine, BV, lenalidomide. Table 1 shows the demographic and treatment details of the patients with HL.

\section{NHL cases}

Among these cases, twelve had diffuse large B cell lymphoma (DLBCL), 6 had peripheral T cell lymphoma (PTCL), 3 had grey zone lymphoma between DLBCL and HL and one had anaplastic lerge cell lymphoma (ALCL).

\section{DLBCL cases}

Male/female ratio was 6/6, age range was 30-77, mean $48.9 \pm 13.3$, R-GVP was given as second line salvage in all but one case. Relapse had been detected in seven cases less than 12 months from the end of first line R-CHOP therapy; CR, PR and PD were detected in 1, 2 and 4 cases, respectively. ASCT was rejected by the patients and response durations were 5, 6 and 7 months in CR and PR patients but they died in spite of second line salvage regimens. Relapse occurred in five cases more than 12 months from the end of first line therapy. PR was detected in only one case and radiation was used for local relapse and she is alive. Cases with PD died in spite of third line salvage treatments.

\section{PTCL cases}

Three of 6 cases received GVP as first and 3 received as second line salvage regimen. Two of these cases had transformed disease from mycosis fungoides. Relapse developed less than 12 months after first line treatment in all cases, except one. Minimal response was detected in one case and he lost to follow up. PR was detected in one case, but she died after 4 months. PD was detected in 4 cases; 2 died and new treatments were planned in 2 cases.

Table 1. Demographic and treatment details of the patients with HL.F: female, M: male, NS: nodular sclerosing, MC: mixed cellular, NC: not characterized, ABVD: doxorubicin-bleocinvinblastine-DTIC, CR: complete response, PR: partial response, PD: progressive disease, MR: minimal response, GVP: Gemcitabine-vinorelbine-prednisolone, DHAP: dexamethasone, Ara-C-cisplatinum, ICE: ifosfamide-carboplatin-etoposide, IGEV: ifosfamide-gemcitabine-vinorelbine, PEPC: procarbazine-etoposide-prednisolone-cyclophosphamide, BV: brentuximab vedotine, ASCT: autologous stem cell transplantation, A: alive, E: exitus, LFU: lost to follow up.

\begin{tabular}{|c|c|c|c|c|c|c|c|c|c|c|c|}
\hline $\begin{array}{l}\text { Patient } \\
\text { Number }\end{array}$ & Age & Sex & Stage & $\begin{array}{c}\text { Subytpe } \\
\text { First } \\
\text { treatment }\end{array}$ & $\begin{array}{l}\text { Response to } \\
\text { 1. treatment }\end{array}$ & $\begin{array}{l}\text { Relapse } \\
\text { Date } \\
\text { (Month) }\end{array}$ & $\begin{array}{l}\text { 1.treatment at relapse/response/ } \\
\text { response duration (month) }\end{array}$ & $\begin{array}{c}\text { 2.treatment at } \\
\text { relapse/response/ } \\
\text { response duration } \\
\text { (month) }\end{array}$ & $\begin{array}{l}\text { Treatment after } \\
\text { GVD/Response }\end{array}$ & $\begin{array}{c}\text { Survival } \\
\text { time } \\
\text { (month) }\end{array}$ & $\begin{array}{c}\text { Last } \\
\text { status }\end{array}$ \\
\hline 1 & 50 & $\mathrm{~F}$ & II-B & NS/ABVD & $\mathrm{CR}$ & $>12$ & GVP / CR / 4 & Nivolumab & Nivolumab & $63+$ & $\mathrm{A}$ \\
\hline 2 & 58 & M & II-A & $\mathrm{MC} / \mathrm{ABVD}$ & $\mathrm{CR}$ & $>12$ & GVP / CR / 25+ & - & - & $64+$ & $\mathrm{A}$ \\
\hline 3 & 59 & M & III-B & NS/ABVD & PR & $<12$ & GVP / PD & Bendamustine / PD & $\mathrm{BV} / \mathrm{PD}$ & 16 & $\mathrm{E}$ \\
\hline 4 & 39 & M & II-B & NS/ABVD & Refractory & - & DHAP / PD & GVP / PD & $\mathrm{BV} / \mathrm{PD}$ & 12 & $\mathrm{E}$ \\
\hline 5 & 20 & $\mathrm{~F}$ & IV-B & NC/ABVD & $\mathrm{CR}$ & $>12$ & DHAP / PD & GVP / PR & ASCT & $102+$ & A \\
\hline 6 & 50 & M & II-B & NC/ABVD & $\mathrm{CR}$ & $<12$ & $\mathrm{ICE} / \mathrm{PD}$ & GVP / PR / 5 & $\mathrm{BV} / \mathrm{PD}$ & 59 & $\mathrm{E}$ \\
\hline 7 & 57 & M & III-B & MC/ABVD & $\mathrm{CR}$ & $>12$ & DHAP / PR & GVP / PD & - & 75 & $\mathrm{E}$ \\
\hline 8 & 22 & $\mathrm{~F}$ & $\mathrm{I}-\mathrm{A}$ & NS/ABVD & $\mathrm{CR}$ & $>12$ & DHAP / PR & GVP / PR / 25 & $\begin{array}{l}\text { BV-Bendamustine- } \\
\text { Nivolumab }\end{array}$ & $144+$ & A \\
\hline 9 & 21 & $\mathrm{~F}$ & II-A & NS/ABVD & Refractory & - & DHAP / PD & GVP / PD & - & 13 & E \\
\hline 10 & 46 & $\mathrm{~F}$ & $\mathrm{I}-\mathrm{A}$ & MC/ABVD & PR & $<12$ & DHAP / PR & GVP / CR / 35 & IGEV-BV & 93 & $\mathrm{E}$ \\
\hline 11 & 49 & M & II-A & NS/ABVD & $\mathrm{CR}$ & $>12$ & DHAP / CR & GVP / PD & - & 41 & $\mathrm{E}$ \\
\hline 12 & 37 & M & II-A & NC/ABVD & $\mathrm{CR}$ & $<12$ & DHAP / PD & GVP / PD & & & LFU \\
\hline 13 & 58 & $\mathrm{~F}$ & IV-B & MC/ABVD & PR & $<12$ & DHAP / PR & GVP / PR / 6 & PEPC & 33 & $\mathrm{E}$ \\
\hline 14 & 23 & M & III-B & NS/ABVD & $\mathrm{CR}$ & $>12$ & DHAP / PR & GVP / CR / 90+ & - & $133+$ & A \\
\hline 15 & 30 & $\mathrm{~F}$ & III-B & NS/ABVD & Refractory & - & DHAP / PD & GVP / CR & ASCT & $118+$ & $\mathrm{A}$ \\
\hline 16 & 57 & $\mathrm{~F}$ & III-B & NS/ABVD & CR & $>12$ & DHAP / PD & GVP / PR / 12 & - & 34 & $\mathrm{E}$ \\
\hline 17 & 29 & M & III-A & NS/ABVD & PR & $>12$ & DHAP / PR & GVP / PR / 6 & - & 24 & $E$ \\
\hline 18 & 27 & $\mathrm{~F}$ & IV-B & NS/ABVD & $\mathrm{CR}$ & $>12$ & DHAP / PD & GVP / PD & $\begin{array}{c}\text { BV-Bendamustine } \\
\text {-ASCT }\end{array}$ & $77+$ & A \\
\hline 19 & 54 & $\mathrm{~F}$ & I-A & NC/ABVD & $\mathrm{CR}$ & $>12$ & DHAP / CR & GVP / PR / 6 & Bendamustine & $75+$ & $\mathrm{A}$ \\
\hline 20 & 27 & M & III-A & NC/ABVD & $\mathrm{CR}$ & $>12$ & DHAP / CR & GVP / CR / 30+ & - & $94+$ & $\mathrm{A}$ \\
\hline 21 & 27 & M & III-A & NS/ABVD & PR & $<12$ & ICE-ASCT / PR & GVP / PD & $\begin{array}{l}\text { BV- } \\
\text { Bendamustine- } \\
\text { Lenalidomide }\end{array}$ & 70 & $\mathrm{E}$ \\
\hline 22 & 49 & M & IIIB & NS/ABVD & $\mathrm{CR}$ & $>12$ & Radiation / CR & GVP / CR / 6+ & - & $284+$ & $\mathrm{A}$ \\
\hline
\end{tabular}




\section{ALCL case}

PR was detected in this case and ABVD was given as third line therapy and he is alive.

\section{DLBCL/HL cases}

R-GVP was given as second line in 2 cases and as third line salvage in one case. All of these cases PD developed, and they died. Table 2 shows the demographic and treatment details of the patients with NHL.

\section{Discussion}

Salvage chemotherapy and high dose chemotherapy supported by ASCT is the standard of care in cases with R/R lymphoma. However, there is no standard or optimum salvage regimen in these cases. DHAP and ICE are the most commonly used regimens. Gemcitabin containing regimens may be effective, cheaper and non-toxic alternatives in cases with $\mathrm{R} / \mathrm{R}$ lymphoma and may be used in outpatient clinics.

Gemcitabine is a cytarabine analog and is a pyrimidine antimetabolite inhibiting DNA synthesis $[10,11]$. Gemcitabine containing regimens are more effective than single agent gemcitabine and most commonly used drugs in these regimens are vinorelbine, doxorubicine, ifosfamide, cisplatinum and steroids [12-15].

GDP (gemcitabine-dexamethasone-cisplatinum) is an active regimen in cases with $\mathrm{R} / \mathrm{R}$ lymphoma, with response rates as high as $50 \%$ and $70 \%$ in NHL and HL, respectively. Stem cell mobilization is feasible with this regimen and GDP has been found non-inferior to DHAP regimen which is most commonly used salvage regimen as mentioned before [16-19]. In a large study containing 235 patients GDP has been used in cases with $\mathrm{R} / \mathrm{R}$ lymphomas and response rate has been found to be $49 \%$ and $71 \%$ in cases with NHL and HL, respectively with accept- able toxicity profile [20]. IGEV is another option in RR cases with HL with acceptable toxicity profile and feasible for stem cell collection [21]. Doxorubicine has been used in some series in addition to gemcitabine and vinorelbine with variable doses and intervals. Response rates have been found as $65.2 \%$ in cases with R/R T cell lymphoma, $48.6 \%$ in $\mathrm{R} / \mathrm{R}$ NHL and $70-80 \%$ in R/R HL [22-24]. Although these regimens have been found to be highly effective, doxorubicine using may be problem in some cases. It is very well known that ABVD and R-CHOP which are standard regimens for HL and NHL for first line therapy. For this reason, doxorubicine containing gemcitabine-vinorelbine regimens are not feasible in some cases in spite of high response rates. This is important especially in cases with limited cardiac function receiving this drug in first line setting.

Gemcitabine, vinorelbine and steroid containing regimens have been used in some series, but number of the patients is limited in these series. Rituximab has been added to gemcitabine and vinorelbine in 4 cases with TCRBCL and 3 CR and 1 PR have been reported [25]. Gemcitabine-vinorelbine-prednisolone (GVP) regimen has been used in 50 cases with R/R HL and response rate has been found as $77.5 \%$ in evaluable 4 cases [26]. In our analysis CR has been found in 2 of 3 cases with R/R HL when used as first line salvage regimen. Both of 2 cases achieving CR rejected ASCT; response duration was 4 months in one and 25 months in other case. Although the number of the patients are limited, this suggests that GVP is highly active salvage regimen in cases with R/R HL. In our cases, 19 cases receiving GVP as second line salvage regimen, CR was detected in one case with primary refractory HL which is difficult to treat. This case is alive at $118+$ months and this is very important for these cases due to the difficulty of the therapy of these cases. Long term survival as long as 90 months was achieved in our cases achieving CR and PR in cases relapsing more than 12 months. These results suggest that GVP is feasible regimen in cases with late

Table 2. Demographic and treatment details of the patients with NHL. F: female, M: male, DLBCL: diffuse large B cell lymphoma, PTCL: peripheral T cell lymphoma, PTCL Tr: peripheral T cell lymphoma transformed disease, ALCL: anaplastic large cell lymphoma, CR: complete response, PR: partial response, PD: progressive disease, MR: minimal response, GVP: Gemcitabine-vinorelbine-prednisolone, R: rituximab, DHAP: dexamethasone, Ara-C-cisplatinum, ICE: ifosfamide-carboplatin-etoposide, IGEV: ifosfamide-gemcitabine-vinorelbine, IIVP: ifosfamide-idarubicine-vinblastine-prednisolone, PEPC: procarbazine-etoposide-prednisolone-cyclophosphamide, BV: brentuximab vedotine, ASCT: autologous stem cell transplantation, A: alive, E: exitus, LFU: lost to follow up.

\begin{tabular}{|c|c|c|c|c|c|c|c|c|c|c|c|}
\hline $\begin{array}{l}\text { Patient } \\
\text { Number }\end{array}$ & Age & Sex & Stage & $\begin{array}{c}\text { Subytpe/1. } \\
\text { treatment }\end{array}$ & $\begin{array}{l}\text { Response to } \\
\text { 1. treatment }\end{array}$ & $\begin{array}{l}\text { Relapse } \\
\text { Date } \\
\text { (Month) }\end{array}$ & $\begin{array}{c}\text { 1.treatment at relapse/ } \\
\text { response/response duration } \\
\text { (month) }\end{array}$ & $\begin{array}{c}\text { 2.treatment at } \\
\text { relapse/response/ } \\
\text { response duration } \\
\text { (month) }\end{array}$ & $\begin{array}{l}\text { Treatment after } \\
\text { GVD/Response }\end{array}$ & $\begin{array}{c}\text { Survival } \\
\text { time } \\
\text { (month) }\end{array}$ & $\begin{array}{c}\text { Last } \\
\text { status }\end{array}$ \\
\hline 1 & 46 & $\mathrm{~F}$ & II-A & DLBCL/RCHOP & $\mathrm{CR}$ & $>12$ & R-DHAP / PD & R-GVP / PD & - & 90 & E \\
\hline 2 & 77 & $\mathrm{~F}$ & IV-B & DLBCL/R CVP & PD & $<12$ & R-Bendamustine / MR & R-GVP / PD & - & 16 & $\mathrm{E}$ \\
\hline 3 & 30 & $\mathrm{~F}$ & IV-B & DLBCL/RCHOP & $\mathrm{CR}$ & $>12$ & R-DHAP / PD & R-GVP/PD & - & 12 & $\mathrm{E}$ \\
\hline 4 & 69 & $\mathrm{~F}$ & II-A & DLBCL/RCHOP & $\mathrm{CR}$ & $>12$ & R-DHAP / CR & R-GVP / PD & PEPC & 109 & E \\
\hline 5 & 51 & $\mathrm{~F}$ & III-A & DLBCL/RCHOP & PD & $<12$ & R-DHAP / PR & R-GVP / CR / 5 & PEPC & 27 & E \\
\hline 6 & 51 & M & III-A & DLBCL/RCHOP & $\mathrm{PD}$ & $<12$ & R-DHAP / PD & R-GVP / PR / 6 & DICE & 12 & E \\
\hline 7 & 32 & M & IV-B & DLBCL/RCHOP & PR & $<12$ & R-DHAP / PD & R-GVP / PR / 7 & BV & 18 & E \\
\hline 8 & 65 & M & II-A & DLBCL/RCHOP & $\mathrm{CR}$ & $<12$ & R-DHAP / PR & R-GVP / PD & - & 19 & E \\
\hline 9 & 50 & M & III-A & DLBCL/RCHOP & $\mathrm{CR}$ & $>12$ & R-GVD / PD & - & - & 69 & $\mathrm{E}$ \\
\hline 10 & 60 & $\mathrm{~F}$ & III-B & DLBCL/REPOCH & CR & $>12$ & R-Bendamustine / PR & R-GVP / PR & Radiation & $32+$ & A \\
\hline 11 & 52 & M & III-B & DLBCL/RCHOP & $\mathrm{CR}$ & $<12$ & R-DHAP / PD & R-GVP / PD & - & 12 & E \\
\hline 12 & 45 & M & II-A & DLBCL/RCHOP & $\mathrm{PD}$ & $<12$ & R-DHAP / PD & R-GVP / PD & - & 23 & E \\
\hline 13 & 43 & M & III-A & PTCLTr/CHOEP & $\mathrm{CR}$ & $<12$ & GVP / PD & BV planned & & $26+$ & A \\
\hline 14 & 58 & M & III-A & PTCLTr/CHOP & PR & $>12$ & GVP / MR / 2 & & & $?$ & LFU \\
\hline 15 & 35 & $\mathrm{~F}$ & IV-B & PTCL/CHOP & $\mathrm{PD}$ & $<12$ & DHAP / PD & GVP / PD & - & 11 & $\mathrm{E}$ \\
\hline 16 & 18 & M & I-A & PTCL/CHOP & $\mathrm{CR}$ & $<12$ & DHAP / PD & GVP / PD & HD Mtx & 22 & E \\
\hline 17 & 43 & M & IV-B & PTCL/CHOEP & $\mathrm{CR}$ & $<12$ & GVD / PD & Pralatrexate planned & & $14+$ & A \\
\hline 18 & 48 & $\mathrm{~F}$ & IV-B & PTCL/CHOEP & PR & $<12$ & GVP / PR / 4 & - & & 11 & $\mathrm{E}$ \\
\hline 19 & 58 & M & III-A & ALCL/CHOP & $\mathrm{CR}$ & $>12$ & GVP / PR & ABVD & & $65+$ & A \\
\hline 20 & 54 & $\mathrm{M}$ & I-A & DLBCL-HL/RCHOP & $\mathrm{PD}$ & $<12$ & R-ICE / PR & R-GVP / PD & & 13 & $\mathrm{E}$ \\
\hline 21 & 46 & M & III-B & DLBCL-HL/ABVD & $\mathrm{PD}$ & $>12$ & DHAP / PD & GEMOX /PD & R-GVD /PD & 125 & $\mathrm{E}$ \\
\hline 22 & 45 & $\mathrm{~F}$ & IV-B & DLBCL-HL/RCHOP & PD & $<12$ & R-DHAP / PD & R-GVP / PD & IIVP & 34 & $\mathrm{E}$ \\
\hline
\end{tabular}


relapse HL. PR was detected in 2 of 5 cases with early relapse HL and this is an advantage in this high risk disease situation. In conclusion GVP is an important choice in cases with HL both in primary refractory also in early/late relapses.

There is no large study about the efficacy of GVP regimen in cases with DLBCL and we could not compare our results with others. Although more than half of our cases had unfavorable outcome with early relapse, response was not good enough. We used GVP as second line salvage regimen and $2 \mathrm{PR}$ and $1 \mathrm{PR}$ were detected, and remission duration was 5-7 months and ASCT was rejected by our patients. Our results suggest that GVP is not a good choice in cases with DLBCL as second line salvage regimen.

Gemcitabine and vinorelbine with or without steroids have been used in cases with lymphoma especially in cutaneous/noncutaneous $\mathrm{T}$ cell lymphomas but in limited number of the cases. In a small series PR has been detected in 4 of 4 cases with cutaneous T cell lymphoma [27]. We treated 6 cases with PTCL, half in first line and half in second line setting. Although gemcitabine containing regimens have been found to be effective in T cell lymphomas, our results were unsuccessful. This may be due to the early relapse in 5 of 6 cases and also transformed disease status in 2 cases.

We treated 3 cases with grey zone lymphoma with GVP and none of these cases responded. It is very well known that grey zone lymphomas have poor outcome with no response to conventional treatments. We did not find a comparable series at this matter.

In conclusion GVP regimen is feasible and effective salvage regimen with high response rate in cases with $\mathrm{R} / \mathrm{R} \mathrm{HL}$ cases both in first line and second line setting. However this regimen is not found to be good enough in cases with R/R NHL

\section{Conflicts}

No conflicts of interest

\section{Ethical approval}

This study has been approved by Cukurova University Medical Faculty Ethical comitte for non-invasive research.

This is a retrospective analysis, there is no specific informed consent received from the patients for this study. However, all the patients are informed about the medical procedures and therapeutic choices at the admissions.

\section{References}

1. Gisselbrecht C, Glass B, Mounier N, Singh Gill D, Linch DC, et al. (2010) Salvage regimens with autologous transplantation for relapsed large B-cell lymphoma in the rituximab era. J Clin Oncol 28: 4184-4190.

2. Lavoie JC, Connors JM, Phillips GL, Reece DE, Barnett MJ, et al. (2005) High-dose chemotherapy and autologous stem cell transplantation for primary refractory or relapsed Hodgkin lymphoma: long-term outcome in the first 100 patients treated in vancouver. Blood 106: 1473-1478.

3. Gerrie AS, Power MM, Shepherd JD, Savage KJ, Sehn LH, et al. (2014) Chemoresistance can be overcome with high-dose chemotherapy and autologous stemcell transplantation for relapsed and refractory Hodgkin lymphoma. Ann Oncol 25: 2218-2223. [Crossref]

4. Ferme C, Mounier N, Divine M, Brice P, Stamatoullas A, et al. (2002) Intensive salvage therapy with high-dose chemotherapy for patients with advanced Hodgkin's disease in relapse or failure after initial chemotherapy: results of the groupe d'etudes des lymphomes de l'adulte H89 trial. J Clin Oncol 20: 467-475.

5. Soussain C, Souleau B, Gabarre J, Zouabi H, Sutton L, et al. (1999) Intensive chemotherapy with hematopoietic cell transplantation after ESHAP therapy for relapsed or refractory non-Hodgkin's lymphoma: results of a single-centre study of 65 patients. Leuk Lymphoma 33: 543-550.
6. López A, Gutiérrez A, Palacios A, Blancas I, Navarrete M, et al. (2008) GEMOX-R regimen is a highly effective salvage regimen in patients with refractory/relapsing diffuse large-cell lymphoma: a phase II study. Eur J Haematol 80: 127-132. [Crossref]

7. Kewalramani T, Zelenetz AD, Nimer SD, Portlock C, Straus D, et al. (2004) Rituximab and ICE as second-line therapy before autologous stem cell transplantation for relapsed or primary refractory diffuse large B-cell lymphoma. Blood 103: 3684-3688.

8. Gisselbrecht C, Glass B, Mounier N, Singh Gill D, Linch DC, et al. (2010) Salvage regimens with autologous transplantation for relapsed large B-cell lymphoma in the rituximab era. J Clin Oncol 28: 4184-4190.

9. Bartlett NL, Niedzwiecki D, Johnson JL, Friedberg JW, Johnson KB, et al. (2007) Cancer Leukemia Group B. Gemcitabine, vinorelbine, and pegylated liposomal doxorubicin (GVD), a salvage regimen in relapsed Hodgkin's lymphoma: CALGB 59804. Ann Oncol 18: 1071-1079.

10. Santoro A, Bredenfeld H, Devizzi L, Tesch H, Bonfante V, et al. (2000) Gemcitabine in the treatment of refractory Hodgkin's disease: results of a multicenter phase II study J Clin Oncol 18: 2615-2619. [Crossref]

11. Fosså A, Santoro A, Hiddemann W, Truemper L, Niederle N, et al. (1999) Gemcitabine as a single agent in the treatment of relapsed or refractory aggressive non-Hodgkin's lymphoma. J Clin Oncol 17: 3786-3792. [Crossref]

12. Zinzani PL, Venturini F, Stefoni Fina M, Pellegrini C, Derenzini E, et al. (2010) Gemcitabine as single agent in pretreated T-cell lymphoma patients: evaluation of the long-termoutcome. Ann Oncol 21: 860-863.

13. Bai B, Huang HQ, Cai QQ, Wang XX, Cai QC, et al. (2013) Promising long-term outcome of gemcitabine, vinorelbine, liposomal doxorubicin (GVD) in 14-day schedule as salvage regimen for patients with previously heavily treated Hodgkin's lymphoma and aggressive non-Hodgkin's lymphoma. Medical Oncology 30: 350-355.

14. Bartlett NL, Niedzwiecki D, Johnson JL, Friedberg JW, Johnson KB, et al. (2007) Cancer Leukemia Group B. Gemcitabine, vinorelbine, and pegylated liposomal doxorubicin (GVD), a salvage regimen in relapsed Hodgkin's lymphoma: CALGB 59804. Annals of Oncology 18: 1071-1079.

15. Ahn HK, Kim SJ, Hwang DW, Ko YH, Tang T, et al. (2013) Gemcitabine alone and/ or containing chemotherapy is efficient in refractory or relapsed NK/T-cell lymphoma. Investigational New Drugs 31: 469-472.

16. Baetz T, Belch A, Couban S, Imrie K, Yau J, et al. (2003) Gemcitabine, dexamethasone and cisplatin is an active and non-toxic chemotherapy regimen in relapsed or refractory Hodgkin's disease: a phase II study by the national cancer institute of canada clinical trials group. Ann Oncol 14: 1762-1767.

17. Crump M, Baetz T, Couban S, Belch A, Marcellus D, et al. (2004) Gemcitabine, dexamethasone, and cisplatin in patients with recurrent or refractory aggressive histology B-cell non-Hodgkin lymphoma: a phase II study by the national cancer institute of canada clinical trials group (NCIC-CTG). Cancer 101: 1835-1842.

18. Cheung MC, Hay AE, Crump M, Imrie KR, Song Y, et al. (2015) Committee on Economic Analysis and the Hematology Disease Site Committee, NCIC Clinical Trials Group. Gemcitabine/dexamethasone/cisplatin vs cytarabine/dexamethasone/cisplatin for relapsed or refractory aggressive-histology lymphoma: cost-utility analysis of NCIC CTG LY.12. J Natl Cancer Inst.

19. Kuruvilla J, Nagy T, Pintilie M, Tsang R, Keating A, et al. (2006) Similar response rates and superior early progression-free survival with gemcitabine, dexamethasone, and cisplatin salvage therapy compared with carmustine, etoposide, cytarabine, and melphalan salvage therapy prior to autologous stem cell transplantation for recurrent or refractory Hodgkin lymphoma. Cancer 106: 353-360.

20. Moccia AA, Hitz F, Hoskins P, Klasa R, Power MM, et al. (2017) Gemcitabine, dexamethasone, and cisplatin(GDP) is an effective and well-tolerated salvage therapy for relapsed/refractory diffuse large B-cell lymphoma and Hodgkin lymphoma. Leukemia and Lymphoma 58: 324-332.

21. Magagnoli M, Spina M, Balzarotti M, Timofeeva I, Isa L, et al. (2007) IGEV regimen and a fixed dose of lenograstim: an effective mobilization regimen in pretreated Hodgkin's lymphoma patients. Bone Marrow Transplant 40: 1019-1025.

22. Quian Z, Song Z, Zhang H, Wang X, Zhao J, et al. (2015) Gemcitabine, navelbine and doxorubicine as treatment for patients with refractory or relapsed T-cell lymphoma. BioMed Res Int pp. 1-7.

23. Bai B, Huang HQ, Cai QQ, Wang XX, Cai QC, et al. (2013) Promising long-term outcome of gemcitabine, vinorelbine, liposomal doxorubicin (GVD) in 14-day Schedule as salvage regimen for patients with previously heavily treated Hodgkin's lymphoma and aggressive non-Hodgkin's lymphoma. Med Oncol 30: 350-355.15 
Paydas S (2017) Gemcitabine-vinorelbine-prednisolone combination in cases with lymphoma: retrospective analysis

24. Bartlett NL, Niedzwiecki D, Johnson JL, Friedberg JW, Johnson KB, et al. (2007) Gemcitabine, vinorelbine, and pegylated liposomal doxorubicin (GVD), a salvage regimen in relapsed Hodgkin's lymphoma: CALGB 59804. Ann Oncol 18: 1071-1079. [Crossref]

25. Xiros N, Economopoulos T, Valsami S, Rontogianni D, Fountzilas G, et al. (2003) Rituximab in combination with vinorelbine/gemcitabine chemotherapy in patients with primary refractory or early relapsed $\mathrm{T}$ cell rich B celllymphoma. A pilot study. Leuk Res 27: 1097-1099.
26. Naqi N, Ahmad S, Shah I, Khattak J (2013) A multicentre phase-II feasibility study evaluating gemcitabine/vinorelbine / prednisolone combination chemotherapy in relapsed / refractory Hodgkin's lymphoma. J Coll Physicians Surg Pak 23: 397-400.

27. Affandi AM, Blumetti TP, Wells J, Hertzberg M, Fernandez-Penas P (2015) Gemcitabine and vinorelbine treatment in cutaneous T-cell lymphoma in four patients. Aust J Fermatol 56: 294-297.

Copyright: $\mathbb{0} 2017$ Paydas S. This is an open-access article distributed under the terms of the Creative Commons Attribution License, which permits unrestricted use, distribution, and reproduction in any medium, provided the original author and source are credited. 